\title{
Editorial
}

\section{Is there a future for branded medicines?}

For those of us involved in the healthcare arena there is growing concern over the tension between demand for high-quality care and the ability of health systems, whether public or private to pay the bills.

One of the main drivers of this situation is the increasing proportion of the so called 'Old Elderly' part of our society, who require significantly more health expenditure than younger people. A further factor is the emergence of new technologies in medicines and procedures which make it possible to treat hitherto untreatable conditions and to improve the quality of current treatments.

Naturally, when a paying agency assesses these trends, the question arises, 'Can we afford to provide unrestricted care for all?' In large part that was the impetus for the NHS reforms in the United Kingdom that took place in the early 1990s and for the reforms now being enacted in France. There have been a range of strategies used throughout Europe to impose a limiting influence on healthcare cost, but a common factor has been a high level of attention on the cost of medicines. Despite the fact that medicines represent only a small fraction of health costs — around 10 per cent — they are a readily measured target and politically soft. It is less difficult for paying agencies (Governments) to attack a profitable industry, than it is to address inefficiencies in the basic system of delivery. The most recent manifestation of cost control is in the emergence of the idea of 'Evidence Based Medicine' in which all therapeutic interventions should be justifiable on the basis of therapeutic effectiveness and economic efficiency.

The cost of medicines is linked not only to the volume used, but also to the mix between inexpensive older products and more costly modern alternatives. There sits the problem for the modern pharmaceutical brand.

\section{REDUCED IMPACT OF THE BRAND CONCEPT}

Product selection by physicians is becoming ever more constrained by prescribing policies and the need to justify choice based on clear evidence of value. Indeed, there are now experimental decision-support systems such as 'Prescriptor' in Holland and 'Prodigy' in the UK which aim to codify the treatment provided within guidelines of care. This will reduce the diversity of products used and hence the impact of branding for a large proportion of the products currently available to physicians. Indeed if the use of fully integrated care plans becomes widespread - so called disease management - there will be even less latitude to work on the branding of medicines as stand-alone entities.

There can be little doubt that the brand concept as currently applied to medicines is in serious jeopardy.

\section{WHAT CAN BE DONE?}

The pharmaceutical industry will have to-redefine its brand strategies to reflect the imperatives of the more data rational market they now operate in. More emphasis on a value proposition, supported by adjunctive services and support may be one way to redefine brands. Closer attention to the re- 
quirements of purchasers of health as well as the deliverers will become essential in formulating brand strategies. Finally, recognition that there is a growing expertise among patients as information on medicines becomes more accessible may provide new branding opportunities.
We are no longer in a 'doctor knows best' market, but one in which a number of new influences can shape the success or otherwise of a product.
John Starzewski
Editorial Board 